\title{
Accuracy of landmark scalp blocks performed during asleep-awake-asleep awake craniotomy: a retrospective study
}

\author{
Takehito Sato ${ }^{*}$ (D) and Kimitoshi Nishiwaki
}

To the Editor,

Awake craniotomy (AC) is often performed in patients with brain tumors that are present in regions linked to language processing to minimize any damage to language functioning [1]. During ACs, scalp blocks affecting the supraorbital nerve, supratrochlear nerve, greater and lesser occipital nerve, auriculotemporal nerve, and zygomaticotemporal branch nerve enable safe surgical procedure during the awake phase of $\mathrm{ACs}[1,2]$. If the scalp block is not effective, it becomes difficult to perform any awake tasks with the cooperation of the patient, as performance is hindered due to headache.

Scalp blocks in ACs are often performed under general anesthesia; however, at our hospital, we perform scalp blocks before the patient is anesthetized to achieve less headache during the awake phase [3]. If the block effect is insufficient as no sensation reduction is demonstrated by the cold test after blocking, an additional dosage of local anesthetic can be administered. To date, no study has considered the accuracy of scalp blocks performed by landmark methods. In this study, we retrospectively investigated the accuracy of scalp blocks performed using the landmark method in ACs.

This study was approved by the Ethics Committee of Nagoya University (Approval number: 2020-0108). We investigated retrospective cases of ACs $(n=103)$ performed at Nagoya University Hospital from January 1, 2016, to May 30, 2020. We performed all scalp blocks bilaterally by landmark methods as described previously with $0.375 \%$ ropivacaine $[1,3]: 1.5-2 \mathrm{~mL}$ for supraorbital/ supratrochlear nerves, $2-2.5 \mathrm{~mL}$ for greater/lesser occipital nerves, $3-5 \mathrm{~mL}$ for auriculotemporal nerve, and $3-5 \mathrm{~mL}$ for zygomaticotemporal branch nerve (total number, 206).

\footnotetext{
* Correspondence: takesato@med.nagoya-u.ac.jp; takeoffflutter@yahoo.co.jp Department of Anesthesiology, Nagoya University hospital, 65 Tsurumai-cho, Showa-ku, Nagoya City, Aichi 466-8550, Japan
}

After all of the scalp blocks were performed, we assessed the number of block failures on each side by using the cold test before induction. We compared the number of block failures using Cochran's $Q$ test. The statistical analyses were performed with EZR (Saitama Medical Center, Jichi Medical University [4]). All data were analyzed using Cochran's $Q$ test and McNemar test with the post hoc Bonferroni test. $P<0.05$ was considered statistically significant.

The rates of failure in the scalp blocks were as follows: supraorbital and supratrochlear nerve $(n=5$, failure rate $2.4 \%)$, greater and lesser occipital nerve $(n=15,7.2 \%)$, auriculotemporal nerve $(n=23,11.1 \%)$, and zygomaticotemporal branch $(n=34,16.6 \%)$.

Among these blocks, the zygomaticotemporal nerve block failure rate was significantly higher than in other nerves $(P<0.001$, at the Cochran's $Q$ test, versus supraorbital and supratrochlear nerve $(P<0.001)$, greater and lesser occipital nerve $(P<0.001)$, auriculotemporal nerve $(P=0.015))$.

This study revealed the failure rate for zygomaticotemporal nerve blocks was higher than that of the other nerve blocks. The zygomaticotemporal nerve is distributed deep below the surface of the skin and can have anomalies $[5,6]$; therefore, it can be difficult to anesthetize using the anatomical landmark method. Patients often suffer headaches during $\mathrm{AC}$, and as the zygomaticotemporal nerve is a nerve responsible for the sensation in the surrounding temple [6], it may be the cause of temporal pain during an AC.

To improve the success rate of the zygomaticotemporal nerve, further studies assessing different blocking techniques, such as using ultrasounds, are required in the future.

\section{Springer Open}

(- The Author(s). 2021 Open Access This article is licensed under a Creative Commons Attribution 4.0 International License, which permits use, sharing, adaptation, distribution and reproduction in any medium or format, as long as you give appropriate credit to the original author(s) and the source, provide a link to the Creative Commons licence, and indicate if changes were made. The images or other third party material in this article are included in the article's Creative Commons licence, unless indicated otherwise in a credit line to the material. If material is not included in the article's Creative Commons licence and your intended use is not permitted by statutory regulation or exceeds the permitted use, you will need to obtain permission directly from the copyright holder. To view a copy of this licence, visit http://creativecommons.org/licenses/by/4.0/. 
Acknowledgements

We would like to thank Editage (www.editage.com) for the English language editing.

\section{Authors' contributions}

TS wrote the manuscript and contributed to the research conception and design, acquisition, analysis, and interpretation of the data. NK contributed to the drafting of the article. The two authors read and approved the final manuscript.

\section{Funding}

Not applicable.

\section{Availability of data and materials}

They are available as an Excel ${ }^{\circledR}$ file upon reasonable request.

\section{Ethics approval and consent to participate}

Our study was approved by the Ethics Committee of Nagoya University Hospital (Approval number: 2020-0108). Because of the retrospective nature of this study, the requirement for informed consent was waived.

\section{Consent for publication}

Not applicable.

\section{Competing interests}

All authors did not receive financial aid for this work and declare no conflicts of interest.

Received: 6 October 2020 Revised: 3 January 2021

Accepted: 4 January 2021 Published online: 09 January 2021

\section{References}

1. Costello TG, Cormack JR. Anaesthesia for awake craniotomy: a modern approach. J Clin Neurosci. 2004;11:16-9.

2. Darreul S, Martin S. Awake craniotomy: anesthetic considerations based on outcome evidence. Curr Opin Anaesthesiol. 2019;32:546-52.

3. Sato T, Okumura T, Nishiwaki K. Preanesthesia scalp blocks reduce intraoperative pain and hypertension in the asleep-awake-asleep method of awake craniotomy: a retrospective study. J Clin Anesth. 2020;66:109946.

4. Kanda T. Investigation of the freely available easy-to-use software 'EZR' for medical statistics. Bone Marrow Transplant. 2013;48:452-8.

5. Totonchi A, Pashmini N, Guyuron B. The zygomaticotemporal branch of the trigeminal nerve: an anatomical study. Plast Reconstr Surg. 2005;115:273-7.

6. Janis JE, Hatef DA, Thakar $\mathrm{H}$, et al. The zygomaticotemporal branch of the trigeminal nerve: Part II. Anatomical variations. Plast Reconstr Surg. 2010;126:435-42.

\section{Publisher's Note}

Springer Nature remains neutral with regard to jurisdictional claims in published maps and institutional affiliations.

\section{Submit your manuscript to a SpringerOpen ${ }^{\circ}$ journal and benefit from:}

- Convenient online submission

- Rigorous peer review

- Open access: articles freely available online

- High visibility within the field

- Retaining the copyright to your article 